\title{
AÇÕES DA SUDECO NO DESENVOLVIMENTO DO CENTRO-OESTE NO ESTADO DE GOIÁS
}

\author{
SUDECO ACTIONS IN THE DEVELOPMENT OF THE CENTRO-OESTE \\ IN GOIÁS STATE
}

\author{
ACCIONES DE LA SUDECO EN EL DESARROLLO DEL CENTRO-OESTE \\ EN EL ESTADO DE GOIÁS \\ Marcelo Antunes Cavalcanti - Instituto Federal Goiano - Goiânia - Goiás - Brasil \\ marceloantunesufg@yahoo.com.br \\ Celene Cunha Monteiro Antunes Barreira - Universidade Federal de Goiás - Goiânia - Goiás - Brasil \\ branca@iesa.ufg.br
}

\begin{abstract}
Resumo
A Superintendência de Desenvolvimento do Centro-0este (SUDECO) desempenhou um papel importante na produção do território goiano. Aproximadamente por uma década 1975/1985 Goiás foi palco de dois grandes programas implementados por este órgão: o Programa de Desenvolvimento das Áreas de Cerrado (POLOCENTRO), criado com o objetivo de ocupar as zonas com cobertura vegetal predominante de Cerrado, incorporando estas terras à fronteira agrícola, a partir do emprego de modernas técnicas de produção; e 0 Programa da Região Geoeconômica de Brasília (PERGEB), que norteou ações no sentido de desenvolver as áreas limítrofes ao Distrito Federal, formando uma "zona tampão" que preservasse o caráter político, administrativo e cultural arquitetado para a capital da República.
\end{abstract}

Palavras-chave: SUDECO, Goiás, planejamento governamental.

\begin{abstract}
The Superintendência de Desenvolvimento do Centro-0este - SUDECO - played an important role in the production in the state of Goiás. For nearly a decade, during the 1975/1985 period, Goiás took the center stage in two big programs implemented by this body: the Program for Development of Areas of Cerrado POLOCENTRO - established with the objective of occupying areas with predominantly cerrado vegetation cover, incorporating these lands into the agricultural frontier, owing to the use of modern techniques of production; and the Program for the Geographical and Economical Region of Brasilia - PERGEB - who directed actions to develop the areas bordering the Federal District, forming a "buffer zone" in order to preserve the political, administrative and cultural characters, originally conceived for the federal capital.
\end{abstract}

Key words: SUDECO, Goiás, governmental planning.

\section{Resumen}

La Superintendência de Desenvolvimento do Centro-Oeste - SUDECO - tuvo un papel importante en el segmento productivo en el territorio goiano. Aproximadamente por una década 1975/1985 Goiás fue el escenario de dos de los grandes programas implementados por esta entidad: El Programa de Desarrollo de las Areas del Cerrado (Ecoregion de la sabana Brasilera) - POLOCENTRO -, creado con el objetivo de ocupar las zonas con cobertura vegetal predominante de la vegetación de cerrado, incorporando estas tierras a la frontera agrícola, a partir del uso de técnicas modernas de producción; y el Programa da Região Geoeconômica de Brasília - PERGEB -, que direccionó acciones en el sentido de desarrollar áreas limítrofes al Distrito Federal, formando una "zona amortecedora" preservando el caráter político, administrativo y cultural arquitectado para la capital de la república.

Palabras clave: Sudeco, Goiás, planeación gubernamental. 
Introdução

A região Centro-Oeste, e particularmente o estado de Goiás, sofreu grandes intervenções estatais, principalmente por parte da União, responsável pela redefinição dos contornos territoriais e pela estruturação de toda a moderna base produtiva. O objetivo desse artigo é o de dimensionar as transformações socioeconômicas processadas no território goiano a partir da atuação da Superintendência de Desenvolvimento do CentroOeste (SUDECO) durante o período de 1975-1985, nas áreas abrangidas pelos Programas POLOCENTRO e Região Geoeconômica de Brasília PERGEB. Esse órgão, Sudeco, foi criado em 1967 e tinha como principal meta a ocupação produtiva, baseada na agropecuária mecanizada, de uma vasta área localizada na porção central do país, recoberta originalmente pelos cerrados.

O Brasil Central, por muito tempo praticamente isolado dos grandes centros urbanos do país, sempre foi compreendido como uma zona de "vazio" demográfico, mas com grande potencial de crescimento econômico, sobretudo relacionado ao desenvolvimento das atividades agropecuárias. Os discursos de legitimação da ocupação produtiva dessa região justificaram-se, também, pela intenção de povoamento da Amazônia, enquanto etapa futura via marcha da fronteira agrícola em direção ao norte; pela absorção de "excedentes populacionais" provindos de áreas estagnadas economicamente, com ênfase ao semiárido nordestino; e como forma de proteção ao eventual avanço da "frente platina" proveniente do Paraguai e da Bolívia, via penetração pelo Mato Grosso e Mato Grosso do Sul. Tais concepções são patentes dentro dos discursos oficiais do Estado brasileiro ao longo da história republicana.

Em um conjunto de palestras realizadas ao longo das décadas de 1950 e 1960, um estrategista do período militar, general Golbery do Couto e Silva se expressou, resumindo em linhas gerais a ideia de manobra geopolítica para integrar o território nacional: "trata-se de inundar de civilização a Hiléia amazônica, a coberto dos nódulos fronteiriços, partindo de uma base avançada constituída no Centro-Oeste" (SILVA, 1981, p. 47). Esse mesmo autor completa:

Deve-se promover a integração da península do Centro-Oeste brasileiro, equipando-a de meios que lhe permitam desempenhar seu duplo papel de sólida plataforma para um transbordamento sobre a 
Hiléia ou para ações visando a contrapor-se ao avanço para o norte de um imperialismo platino. Para a realização de tão ingente tarefa, contamos com uma população jovem, de elevado ritmo de crescimento e elevado grau de homogeneidade. (SILVA, 1981, p. 60-61)

Desde a década de 1930, o Governo Federal vinha imprimindo uma política de ocupação e povoamento dessa porção do território nacional. Marcos importantes dessa política foram a construção de Goiânia, a implantação das Colônias Agrícolas Nacionais de Goiás e Dourados (MS) e a Expedição Roncador-Xingu, assim como a transferência da Capital Federal, acompanhada por um grande programa rodoviário de forte impacto na integração física da região com o restante do país.

Em 1960, a região Centro-Oeste representava mais de 22\% da área do território nacional, mas continha apenas $4 \%$ da população brasileira. Desse modo, a ocupação dessa área passou a ser uma referência de primeira grandeza dentro da estratégia de integração do território nacional durante o período da Ditadura Militar.

A expansão da fronteira agrícola no Centro-Oeste brasileiro deve ser compreendida a partir do pronto atendimento do Estado à reivindicação do segmento industrial e dos grupos multinacionais que passaram a investir grande soma de recursos depois da II Guerra Mundial em pesquisas agropecuárias, melhoramento genético, adubação e fertilização de solos, mecanização da agricultura etc. Esses oligopólios objetivavam ampliar a dependência da agricultura para com a indústria e passaram a reivindicar do setor público, sobretudo dos países subdesenvolvidos, ações governamentais que promovessem a expansão da fronteira agrícola, nos moldes da moderna agropecuária, justificando tais medidas como a única opção para acabar com a fome no mundo.

\section{A criação da Superintendência de Desenvolvimento do Centro-Oeste (SUDECO)}

A Superintendência de Desenvolvimento da Região Centro-Oeste (SUDECO) foi criada oficialmente pela Lei n. 5.365, de $1^{\circ}$ de dezembro de 1967 (BRASIL, 1967). A principal missão da Sudeco seria elaborar e coordenar, em entendimento com os demais órgãos da região, planos diretores de desenvolvimento regional. O II Plano Nacional de Desenvolvimento - PND ${ }^{1}$ (1974), elaborado durante a Crise do Petróleo, reafirmou de modo enfático o papel da região Centro-Oeste quanto à necessidade de aumento 
da produção agrícola e absorção de "excedentes populacionais". Preocupado com o controle da balança de pagamentos, em decorrência da crise econômica mundial desse período, o Estado brasileiro tomou a iniciativa de intensificar a ocupação produtiva do Centro-Oeste e da Amazônia, como se pode depreender do discurso governamental:

Trata-se agora de exigir muito mais da agropecuária [...]. Significa, de um lado, efetivar a vocação do Brasil como supridor mundial de alimentos, matérias-primas agrícolas e produtos agrícolas industrializados [...]. Cabe recordar que o Brasil, no quadro mundial, é um dos poucos países ainda com ampla disponibilidade de espaço. A ocupação de novas áreas deverá continuar, como processo importante de expansão da agropecuária, dada a existência de terras relativamente férteis para deslocamento da fronteira agrícola, tendo em vista que o gigantesco sistema viário já construído, colocou à disposição do setor imensas áreas no Centro-Oeste e na Amazônia. (BRASIL, 1974, p. 33)

\section{Programa de Desenvolvimento dos Cerrados (POLOCENTRO)}

Em meados da década de 1970, pesquisas realizadas pela EMBRAPA haviam constatado que cerca de 50 milhões de hectares recobertos pelo cerrado eram aptos às atividades agrícolas (BRASIL, 1975). As limitações consistiam apenas em fatores pedológicos. Em 1975, a área cultivada em todo o país girava em torno de 40 a 45 milhões de hectares. Ou seja, a área do Cerrado brasileiro com reais possibilidades de ocupação era superior ao somatório de toda a terra cultivada até então no país.

Nesse contexto, foi criado em 1975, através do Decreto $\mathrm{n}^{0} 75.320$ o Programa de Desenvolvimento do Cerrado (POLOCENTRO). Esse Programa tinha como objetivo incorporar às atividades do setor primário, apenas entre os anos de 1975 a 1979 - período de vigência do II PND -, a cifra de 3,7 milhões de hectares de cerrados (BRASIL, 1975). Segundo a EMBRAPA, a ocupação dessa área seria inviável a partir do manejo tradicional da terra, sendo reservada, portanto, à agropecuária moderna, em padrões comerciais.

Nos documentos oficiais que versam sobre o POLOCENTRO é muito presente a imagem da região Centro-Oeste como solução para os dilemas brasileiros. Ao mesmo tempo, a região foi vendida como promessa de bonanças. 
A região Centro-Oeste [...] cumprirá um importante papel, quanto à solução dos grandes problemas nacionais: crescimento da renda e do emprego, redução das disparidades regionais, contenção da inflação, equilíbrio da balança de pagamentos, desenvolvimento do setor energético e absorção de migrações internas no país. (BRASIL, 1984, p. 35)

Os projetos da SUDECO trouxeram o conceito dos "Polos de Crescimento", elaborado pelo economista francês François Perroux. Os investimentos do POLOCENTRO foram aplicados em áreas-programa e não em todo o estado de Goiás. Segundo Geraldo de Alencar, "essas áreas então, servirão como pólos de desenvolvimento, de modo que possam irradiar para as regiões vizinhas uma agricultura bastante desenvolvida" (BRASIL, 1975, p. 31). Em Goiás, foram selecionadas cinco áreas-programa: Rio Verde, Piranhas, Pirineus, Paranã e Gurupi (Figura 1).

Figura 1 - Áreas selecionadas para recebimento de recursos do programa POLOCENTRO.

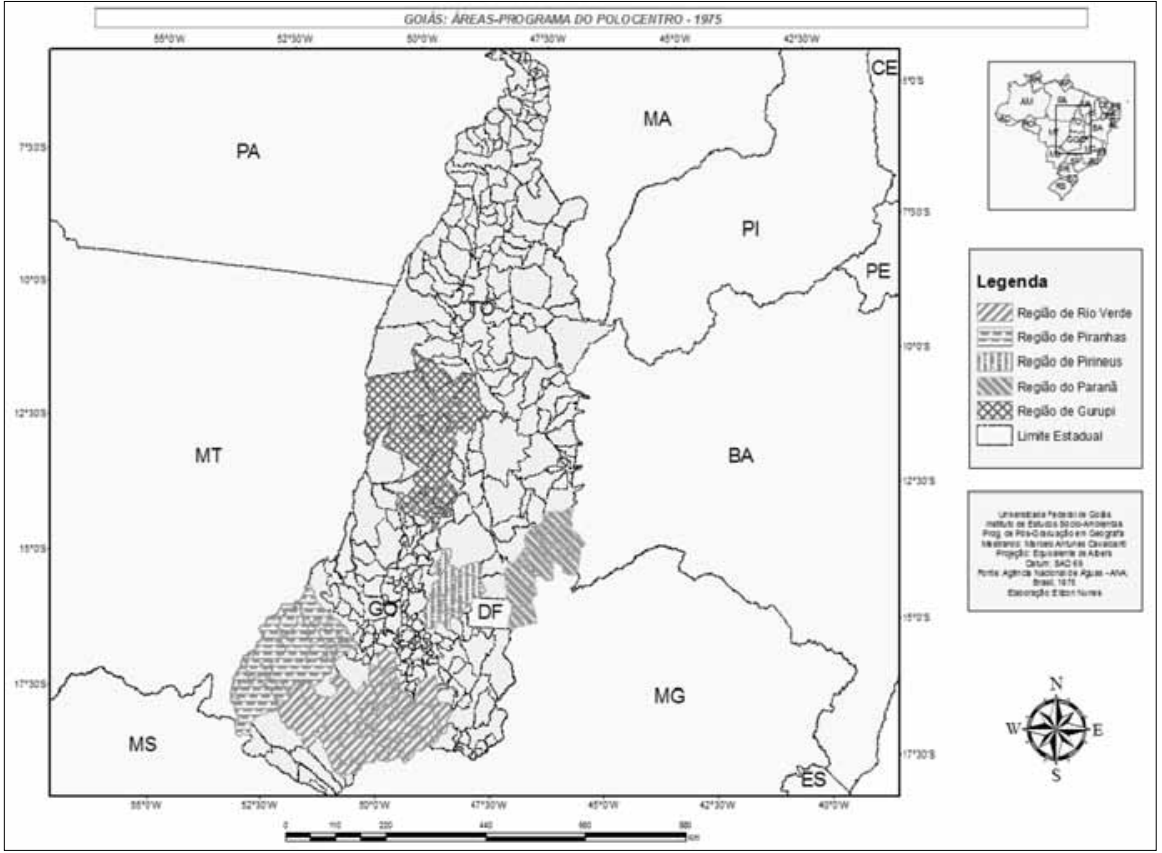


Em Goiás, os proprietários com até 100 hectares captaram apenas 0,5\% dos recursos do Programa (Figura 2), enquanto os latifundiários com área superior a 1000 hectares absorveram $62 \%$ de todo o montante de recursos destinados ao crédito agrícola.

\begin{tabular}{|l|c|c|c|c|}
\hline Propriedades (ha) & $\mathbf{N}^{\mathbf{0}}$ de projetos & Proporção (\%) & Valor Cr\$ 1.000 & Proporção (\%) \\
\hline $0-100$ & 54 & 1,5 & $2.105 .966,4$ & 0,5 \\
\hline $100-200$ & 129 & 10,0 & $10.243 .105,6$ & 3,0 \\
\hline $200-500$ & 324 & 25,2 & $40.344 .343,2$ & 11,0 \\
\hline $500-1000$ & 326 & 25,3 & $72.623 .230,5$ & 20,5 \\
\hline $1000-2000$ & 258 & 20,0 & $90.307 .966,0$ & 26,0 \\
\hline 2000 ou mais & 195 & 15,2 & $138.162 .976,0$ & 39,0 \\
\hline Total & 1286 & 100,0 & $353.787 .588,0$ & 100,0 \\
\hline
\end{tabular}

Figura 2 - Crédito rural aprovado pelo POLOCENTRO em Goiás entre 1975-1982.

Fonte: Fundação João Pinheiro, 1984.

Além de os investimentos terem sido direcionados quase que exclusivamente aos grandes proprietários rurais, houve uma grande concentração espacial desses recursos dentro do estado de Goiás. Desse modo, apenas a área-programa de Rio Verde captou praticamente a metade, $46,8 \%$, de todo o montante do capital remetido aos financiamentos agrícolas (Fundação João Pinheiro, 1984). O poder de retenção desses valores, subsidiados pelo poder público, diz respeito à existência, já naquele momento histórico, de uma classe rural com características empresariais, disposta a atender aos pré-requisitos impostos pelo Programa. Não bastava querer ser beneficiado, mas atender às condições impostas pelos agentes de financiamento. Aventa-se ainda a possibilidade de influência de grupos políticos regionais nos meios decisórios estatais.

Abaixo são apresentados dados sobre a incorporação de terras ao processo produtivo nas áreas-programa do POLOCENTRO no estado de Goiás na década de 1970 (Figura 3). É intrigante observar que em termos percentuais a microrregião de Rio Verde, área que mais recebeu recursos, foi a que proporcionalmente menos incorporou terras. Informações relativas à produtividade provavelmente mostrarão o oposto. 


\begin{tabular}{|l|r|r|r|r|r|r|}
\hline \multirow{2}{*}{ Subáreas } & \multicolumn{3}{|c|}{ Área cultivada (ha) } & \multicolumn{3}{c|}{ Crescimento Acumulado (\%) } \\
\cline { 2 - 7 } & $\mathbf{1 9 7 0}$ & $\mathbf{1 9 7 5}$ & $\mathbf{1 9 8 0}$ & $\mathbf{1 9 7 0 / 7 5}$ & $\mathbf{1 9 7 5 / 8 0}$ & $\mathbf{1 9 7 0 / 8 0}$ \\
\hline Rio Verde & 1.637 .112 & $\mathbf{2 . 0 9 9 . 0 2 0}$ & 2.994 .168 & 28,21 & 42,65 & 82,89 \\
\hline Gurupi & 287.261 & 887.204 & 1247.615 & 208,85 & 40,62 & 334,31 \\
\hline Piranhas & 248.694 & 777.798 & 1.228 .352 & 121,75 & 57,93 & 393,92 \\
\hline Paranã & 170.254 & 321.721 & 477.153 & 88,97 & 48,31 & 180,26 \\
\hline Pirineus & 87.632 & 284.862 & 334.423 & 225,07 & 17,29 & 281,28 \\
\hline POLOCENTRO & 2.430 .953 & 4.370 .605 & 6.281 .411 & 79,79 & 43,72 & 158,39 \\
\hline Goiás & 6.022 .832 & 10.141 .918 & 14.845 .019 & 68,39 & 46,37 & 146,48 \\
\hline
\end{tabular}

Figura 3 - Dados relativos à incorporação de área ao processo produtivo, por regiões-programa no estado de Goiás (1970 e 1980).

Fonte: IBGE, censos agropecuários, Goiás, 1970, 1975 e 1980.

A análise dos dados do POLOCENTRO na região Centro-Oeste e em Goiás nos permite fazer as seguintes observações:

A) O programa logrou êxito: provou que as áreas de cerrado são viáveis economicamente à agricultura comercial, incorporando extensas áreas ao sistema produtivo e transformando o Planalto Central em um dos maiores celeiros mundiais.

B) Ao invés de fixar populações no campo, absorvendo mão de obra de outras regiões do país - uma das intenções da SUDECO -, o POLOCENTRO promoveu um rápido e intenso êxodo rural.

C) Os danos ambientais provocados pela devastação dos cerrados são irreparáveis e o Programa teve uma grande parcela de culpa.

D) A distribuição espacial dos investimentos do Programa, sobretudo o crédito agrícola, beneficiou apenas algumas áreas do estado de Goiás, promovendo a ampliação das disparidades intrarregionais, de modo que o crescimento econômico não se difundiu de forma homogênea, conforme defendia a teoria econômica dos Polos de Crescimento.

E) Apenas uma pequena parcela dos produtores rurais foi beneficiada pelo Programa; de modo geral, as linhas de financiamento agrícola primaram pela seletividade, patrocinando prioritariamente os grandes latifundiários integrados ao mercado. 
As ações do Programa Especial da Região Geoeconômica de Brasília (PERGEB) no território goiano

Brasília foi erguida num dado momento da trajetória do desenvolvimento brasileiro onde a pressa em construir uma nova capital não permitiu análises detalhadas de suas consequências futuras. Destarte, foi implantada a nova capital de um país de dimensões continentais, e transferida a maioria dos órgãos públicos federais, instalando-se desta forma uma importante concentração de capital técnico-científico (Plano Piloto), com recursos humanos de alto poder aquisitivo, em uma área até então incapaz de prover os elementos básicos ao abastecimento da cidade.

Referindo-se à dicotomia entre Brasília e seu entorno, uma cidade de concepção moderna, com uma população de alta renda, exigente de serviços sofisticados, em meio a uma região sem mínimas condições de infraestrutura, o economista Paulo Couto asseverou: "construíra-se um oásis num deserto de pobreza, um 'emirado' sem fronteiras no seio de uma região ainda não alcançada pelos reflexos do desenvolvimento econômico nacional, carente de toda espécie de infraestrutura" (BRASIL, 1981, p. 2).

Preocupado com a situação do crescimento "desordenado" e com a falta de infraestrutura produtiva do entorno do Distrito Federal, o governo do DF criou o Programa da Região Geoeconômica de Brasília (PERGEB) em 1967 e posteriormente, em 1975, transferiu-o para a administração do governo federal, cuja gestão ficou a cargo da SUDECO. O intuito do programa era frear a pressão por emprego, moradia e serviços sobre a nova sede do governo central, dotando seu entorno de condições de desenvolvimento capazes de barrar os fluxos migratórios e diminuir a dependência sobre a capital da República.

A área de atuação do PERGEB foi de $235.573 \mathrm{~km}^{2}$, englobando 87 municípios, sendo 74 no estado de Goiás e 13 em Minas Gerais. Sua concepção baseava-se resumidamente na delimitação de três áreas concêntricas (Figura 4), delineadas a partir da sede do governo federal, cujas ações e prioridades seriam diferenciadas: $1^{\mathrm{a}}$ - interior do DF: Zona de Contenção, em que se deveria promover a estagnação ou pelo menos a diminuição abrupta do crescimento urbano/demográfico; $2^{\mathrm{a}}$ - municípios limítrofes ao DF: Zona de Amortecimento, as ações seriam no sentido de promover o ordenamento urbano e impedir o parcelamento do solo próximo à fronteira com o Distrito Federal; $3^{\mathrm{a}}$ - Abrangência Regional: Zona de Dinamização, 
a intenção era de promover o desenvolvimento de atividades produtivas voltadas ao abastecimento de Brasília em municípios de Goiás e Minas Gerais, como produtos hortifrutigranjeiros e industriais, atividades turísticas de lazer etc. Formar-se-ia um envoltório de proteção à sede do governo federal.

Figura 4 - Área de atuação do PERGEB.

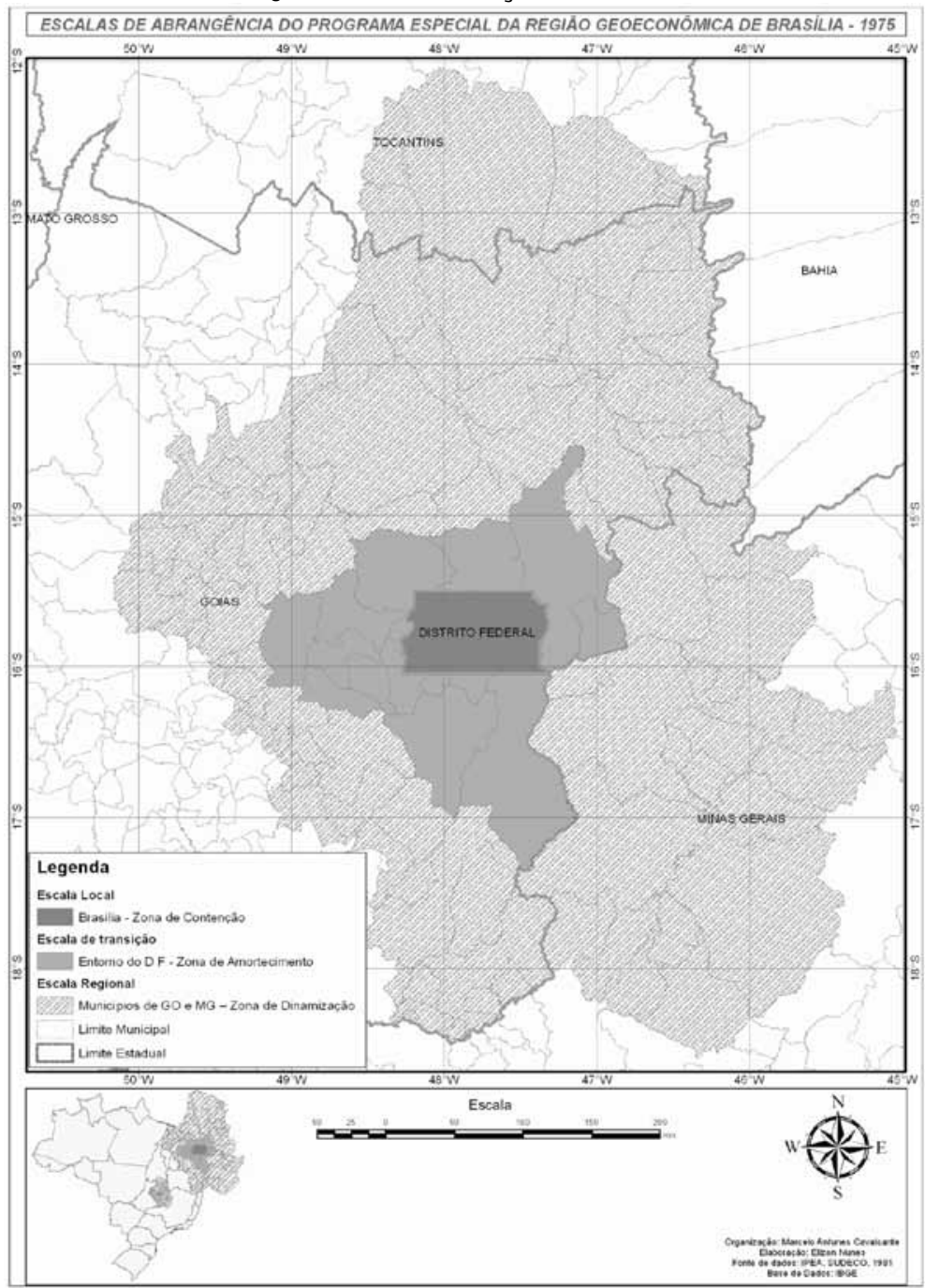


Em um primeiro momento, o que mais chama atenção nas realizações do Programa é a variedade setorial das ações executadas, abrangendo praticamente todos os campos de atuação do poder público, desde a educação até programas voltados à industrialização, em um período onde era necessária a atuação do Estado em inúmeros setores que atualmente já foram entregues à iniciativa privada. Esse aspecto dificulta a análise da evolução do quadro regional. Nesse sentido, serão apenas pontuadas algumas observações referentes ao provável impacto desse Programa na estruturação da região.

Com relação à contenção das migrações para a Capital Federal, já em 1978 o Programa admitiu ser impossível contê-las (TEIXEIRA, 1978). Entretanto, políticas de restrição ao parcelamento e ocupação do solo no interior do Distrito Federal, sobretudo no Plano Piloto, ajudaram a diminuir o impacto sobre a descaracterização do Plano Urbanístico de Brasília. As cidades do entorno do DF cresceram assustadoramente e os principais problemas urbano-sociais da capital da República acabaram sendo transferidos para o estado de Goiás. Durante a década de 1990 houve a criação de novos municípios devido ao adensamento populacional próximo à fronteira com o DF: Águas Lindas, Valparaíso de Goiás, Cidade Ocidental etc., processo que o PERGEB tentou evitar.

A atuação do Programa parece ter ajudado a preservar o caráter terciário de Brasília, pois sem a implantação do Distrito Agroindustrial de Anápolis - uma das maiores realizações do PERGEB, em conjunto com o governo do estado de Goiás - e os incentivos à industrialização e ao desenvolvimento das atividades produtivas fora da região metropolitana, provavelmente Brasília teria funcionado como polo atrativo à implantação de indústrias, devido ao seu forte mercado consumidor. ${ }^{2}$

Nos programas voltados ao setor primário observa-se uma relação conflituosa entre esse programa e o POLOCENTRO. O Programa de Desenvolvimento dos Cerrados tinha como propósito desenvolver a agropecuária mecanizada, enquanto a Geoeconômica incentivava a agricultura familiar voltada ao abastecimento de Brasília, como a produção de hortifrutigranjeiros, com intensa absorção de mão de obra. Isso gerou alguns conflitos, sobretudo quando se tratava de áreas com sobreposição de ações.

De forma geral, o POLOCENTRO visa a critérios de eficiência, e o PERGEB critérios de distribuição [...]. Em todas as intercessões de áreas, o POLOCENTRO deverá observar critérios semelhantes aos 
da Geoeconômica, cuidando para não intensificar o êxodo rural”. (TEIXEIRA, 1978, p. 23)

Nas parcerias do PERGEB com a EMBRAPA e a EMBRATER, a maioria das pesquisas foi voltada ao desenvolvimento de produtos que não se adequavam à pequena propriedade rural, e a assistência técnica trazia consigo a visão do empresário rural, contida na formação dos técnicos (TEIXEIRA, 1978). Apesar dos esforços do Programa, verificouse um quadro marcado pelo êxodo rural, ampliação da pecuarização e intensificação da mecanização, com redução do número de propriedades e concentração fundiária. Todavia, alguns projetos como a introdução da melancia no vale do São Patrício/GO, do alho em Catalão/GO etc., foram ações que ajudaram a delinear o perfil produtivo desses municípios. Os investimentos sociais nas áreas urbanas, notadamente em saúde e educação, provavelmente diminuíram a pressão sobre Brasília. De modo geral, acredita-se que o Programa acabou dando os primeiros passos no sentido de estruturar a região de influência direta da Capital Federal.

\section{Considerações finais}

É importante perceber que a estratégia de ocupar e transformar os Cerrados (Centro-Oeste) em um grande celeiro internacional é exógena ao quadro regional. Ou seja, as mais relevantes decisões, tomadas em última instância pelo Estado brasileiro, que deram origem a um órgão de planejamento destinado exclusivamente à promoção da efetiva ocupação produtiva do Centro-Oeste (SUDECO), não partiram de reivindicações dos atores localizados nessa região, e, sim, dos industriais interessados em vender produtos agrícolas e maquinário, das grandes corporações controladoras do mercado mundial de commodities e dos setores estratégicos do governo federal, principalmente os diplomados pela Escola Superior de Guerra e sua Associação, a ADESG. Naquele período, esses setores estratégicos viam a ocupação desse território - Centro-Oeste - como a solução para alguns problemas do país, possibilitando-lhes inúmeros benefícios, entre eles: o controle da balança de pagamentos, a partir de excedentes comerciais gerados com as exportações de produtos primários; a fixação de populações pobres, sobretudo da região Nordeste; a possibilidade de avanço da "marcha civilizatória" em direção à Amazônia em uma etapa 
futura e a proteção contra a ocupação estrangeira das terras situadas na fronteira com a Bolívia e o Paraguai. Portanto, a estratégia de ocupação do Centro-Oeste foi gestada e articulada de fora para dentro da região.

As principais consequências dos programas da Sudeco, direcionados à modernização da agricultura foram: aumento vertiginoso da produção agropecuária, principalmente de gêneros alimentícios destinados à exportação, concentração fundiária, êxodo rural acelerado e destruição dos ecossistemas naturais do Cerrado, em uma velocidade provavelmente nunca vista anteriormente a nível mundial. Esse processo estruturou na região um quadro propício ao recebimento de plantas industriais, sobretudo a partir da década de 1990, de empresas ligadas ao mercado de commodities, com destaque para o complexo grão-carne, processamento de óleos vegetais e rações etc. Deve-se acrescentar ainda que os investimentos realizados pelo POLOCENTRO foram extremamente centralizados, privilegiando apenas algumas áreas do estado de Goiás e da região Centro-Oeste, de modo que isso colaborou com a ampliação das desigualdades intrarregionais.

Esses grandes programas estruturaram-se a partir de vultosos empréstimos contraídos pelo governo brasileiro no exterior ao longo da década de 1970. A crise mundial que eclodiu com maior intensidade no início da década seguinte diminuiu drasticamente a capacidade de investimento do Estado, provocando nos anos posteriores o processo de desmonte e enxugamento da máquina pública. Portanto, a partir de 1980 os programas da SUDECO sofreram uma forte redução no montante de investimentos aplicados e em 1985 seus projetos foram, na prática, paralisados. Esse processo resultou na extinção da SUDECO no ano de 1990.

\section{Notas}

1. O I PND (Brasil, 1971) não citou a SUDECO nem considerou a região CentroOeste como área prioritária para recebimento de recursos governamentais, frisando apenas o Norte e o Nordeste do país. Mas, norteou diretrizes para expansão da fronteira agrícola rumo à Amazônia e ao Planalto Central. Partindo da concepção de que ocupar e integrar uma região, nesse momento histórico, se fazia primordialmente a partir da construção de estradas e implantação de infraestrutura básica, os programas derivados do I PND com atuação no Centro-Oeste, PROTERRA e o PRODOESTE, conduziram a maior parte dos investimentos para construção e pavimentação de estradas. 
2. Alguns projetos para implantação do DAIA foram realizados já no final da década de 1960, quando a Geoeconômica fazia parte da administração do governo do DF (TIMM, 1990). Em 1975, o PERGEB, que atuava fora da circunscrição do Distrito Federal, foi encampado pelo Governo Federal, ficando a cargo da SUDECO. O DAIA foi inaugurado em 1976 e, provavelmente, muitas das ações para estruturação desse distrito industrial foram realizados em parceria com o programa do governo estadual "Goiás-Industrial".

\section{Referências}

BRASIL. Criação da Superintendência de Desenvolvimento do Centro-Oeste Sudeco. Lei n. 5.365 de $1^{\circ}$ de dezembro de 1967. Brasília, 1967.

BRASIL. I Plano Nacional de Desenvolvimento (PND). Brasília: Imprensa Oficial, 1971.

BRASIL. II Plano Nacional de Desenvolvimento (PND). Brasília: Imprensa Oficial, 1974.

BRASIL. IEncontro de Estudos e Debates: o PND e os programas de desenvolvimento da região do Distrito Federal e do Centro-Oeste. Brasília: Senado Federal, 1975.

BRASIL. Geoeconômica de Brasília: avaliação e proposições. Brasília: IPEA, Sudeco e SEPLAN/GO, 1981. (Circulação interna).

BRASIL. Balanço de realizações e subsídio ao planejamento regional. Brasília: Sudeco, Ministério do Interior, 1984. (Circulação interna).

FUNDAÇÃO JOÃO PINHEIRO. Estudo para a redefinição do Programa de Desenvolvimento dos Cerrados - POLOCENTRO. Belo Horizonte, Secretaria de Planejamento e Coordenação Geral do Estado de Minas Gerais, 1984.

SILVA, Golbery do Couto e. Conjuntura política nacional: o poder executivo \& geopolítica do Brasil. Brasília: Ed. UnB, 1981. (Coleção Temas Brasileiro, n. 7).

TEIXEIRA, Paulo Couto. Região geoeconômica de Brasília: diretrizes para o período 1980 a 1985. Brasília: IPLAN/IPEA, 1978.

TIMM, Paulo. Brasília: o direito à esperança. Brasília: Kuarup, 1990.

Marcelo Antunes Cavalcanti - Mestre em geografia pela Universidade Federal de Goiás. Professor do Instituto Federal Goiano.

Celene Cunha Monteiro Antunes Barreira - Doutora em geografia humana pela Universidade Paulista. Professora da Universidade Federal de Goiás. 